\title{
Evolving Treatment Paradigm in the Management of Diabetic Macular Edema in the Era of COVID-19
}

\author{
Claudio lovino ${ }^{1}$, Enrico Peiretti ${ }^{2}$, Giuseppe Giannaccare ${ }^{3}$, Vincenzo Scorcia ${ }^{3}$ and \\ Adriano Carnevali ${ }^{3 *}$ \\ ${ }^{1}$ Multidisciplinary Department of Medical, Surgical and Dental Sciences, University of Campania Luigi Vanvitelli, Naples, Italy, \\ ${ }^{2}$ Department of Surgical Sciences, Eye Clinic, University of Cagliari, Cagliari, Italy, ${ }^{3}$ Department of Ophthalmology, University of \\ Magna Graecia, Catanzaro, Italy
}

Keywords: COVID-19, intravitreal injection, diabetic macular edema, dexamethason implant, pandemic (COVID19)

\section{OPEN ACCESS}

Edited by:

Mario Damiano Toro, Medical University of Lublin, Poland

Reviewed by: Sibel Demirel, Ankara University, Turkey Dinah Zur,

Tel Aviv Sourasky Medical Center

Israel

${ }^{*}$ Correspondence:

Adriano Carnevali adrianocarnevali@live.it

Specialty section: This article was submitted to Experimental Pharmacology and Drug Discovery,

a section of the journal Frontiers in Pharmacology

Received: 21 February 2021 Accepted: 10 March 2021 Published: 12 April 2021

Citation: lovino C, Peiretti E, Giannaccare G, Scorcia V and Carnevali A (2021) Evolving Treatment Paradigm in the Management of Diabetic Macular Edema in the Era of COVID-19.

Front. Pharmacol. 12:670468. doi: 10.3389/fphar.2021.670468
Intravitreal therapy is widely recognized as a major milestone in ophthalmology being one of the most commonly performed ocular procedures (He et al., 2018). The spread of coronavirus disease (COVID-19) still represents an important public health problem worldwide (Ferrara et al., 2020; Wang et al., 2020). This novel virus infection, is causing a significant downsizing of non-urgent treatments provided for ocular disorders (Tognetto et al., 2020; Toro M. D. et al., 2020, Toro M. et al., 2020), including intravitreal therapy (Elfalah et al., 2021).

Since diabetic retinopathy (DR) still remains the leading cause of blindness among working-age adults (Ting et al., 2016), ophthalmologists should be aware of the potential negative effects of COVID-19 restrictions in the management of diabetic patients in the next months.

The global COVID-19 pandemic led many governments from different nations to adopt protective and strict measures to reduce its spread. In these unprecedented circumstances, many healthcare systems are overwhelmed and under stress.

In this scenario, there is an urgent need to support ophthalmologists who are treating patients with intravitreal injections in decision-making protocols. In order to provide continuity of care, and to reduce the risk of contamination, series of protection measures have been proposed (Iovino et al., 2020a; Borrelli et al., 2020; Korobelnik et al., 2020). Nevertheless, many patients cannot receive a prompt therapy due to all public health restriction measures. During COVID-19 outbreak Carnevali et al. proposed treatment priority levels to treat the most urgent patients, although a drop of $91.7 \%$ of the injections performed compared to the same period of 2019 was registered (Carnevali et al., 2020).

Diabetic patients are considered at high risk for COVID-19 complications and should not be exposed to avoidable risks, including the injections procedure itself. However, continuation of care, where possible, is important to avoid irreversible vision loss.

For non-monocular patients with diabetic macular edema (DME), postponement ( $>4-6$ months) of appointments has been proposed (Korobelnik et al., 2020). As recently reported, postponing treatment in patients with good visual acuity does not affect the prognosis at 1 year, regardless of whether the DME was treated or not (Busch et al., 2019). Conversely, in patients with more advanced DR and worse visual acuity, a delay in treatments could cause irreversible visual loss (Ting et al., 2016; Elfalah et al., 2021).

Anti-vascular endothelial growth factor (VEGF) injections represent generally a first-line therapy for several retinal disorders including DME (Heier et al., 2012; Reibaldi et al., 2014; Schmidt-Erfurth et al., 2017; Plyukhova et al., 2020), but monthly injections are needed at least during the loading dose (Schmidt-Erfurth et al., 2017). Of note, intravitreal dexamethasone (DEX) implant $0.7 \mathrm{mg}$ (Ozurdex ${ }^{\circledR}$, Allergan, Inc. Irvine, CA, United States) is considered a valid alternative for both refractory to anti-VEGF treatment eyes and treatment naïve ones (Iglicki et al., 2019; Iovino et al., 
2020b). Intravitreal DEX implant releases active ingredients within the vitreous chamber over a 3-6 months period, and its efficacy and safety in various retinal diseases have been proved in clinical trials and real-life studies (Maturi et al., 2016; Rajesh et al., 2020). Several authors also reported significant anatomical and functional effects of DEX implant in vitrectomized eyes in different conditions (Boyer et al., 2011; Reibaldi et al., 2012; Iovino et al., 2019). Corticosteroids have multiple levels of action, modifying tight junction integrity, inhibiting different molecules involved in vascular permeability and inflammation processes including interleukin-6, stroma-derived factor-1, Intercellular adhesion molecule-1, as well as VEGF (Iovino et al., 2020b).

All these mechanisms of action work in aggregate, resulting in decreased macular edema and VEGF production, fibrin deposition, capillary leakage and migration of inflammatory cells (Gagliano et al., 2015). There is evidence that oxidative stress, ischemia and inflammation promote the initiation and progression of DR (Toro et al., 2019), further supporting the role of DEX implant in controlling the progression of the DME (Ceravolo et al., 2020).

Cataract progression and intraocular pressure rise are the most common side effects, but often rather easily manageable (Iovino et al., 2020b; Rajesh et al., 2020). Additionally, several optical coherence tomography (OCT) biomarkers were identified as functional outcome predictors in DME eyes treated with DEX implant including the presence of submacular fluid, absence of hyperreflective intraretinal foci and integrity of the ellipsoid zone (Zur et al., 2018).

On this background, a good selection of patients with DME who can benefit from observation or a single intravitreal DEX injection rather than monthly anti-VEGF injections, could be of

\section{REFERENCES}

Borrelli, E., Sacconi, R., Querques, L., Zucchiatti, I., Prascina, F., Bandello, F., et al. (2020). Taking the right measures to control COVID-19 in ophthalmology: the experience of a tertiary eye care referral center in Italy. Eye 34, 1175. doi:10. 1038/s41433-020-0880-6

Boyer, D. S., Faber, D., Gupta, S., Patel, S. S., Tabandeh, H., Li, X.-Y., et al. (2011). Dexamethasone intravitreal implant for treatment OF diabetic macular edema IN vitrectomized patients. Retina 31, 915-923. doi:10.1097/IAE. 0b013e318206d18c

Busch, C., Fraser-Bell, S., Iglicki, M., Lupidi, M., Couturier, A., Chaikitmongkol, V., et al. (2019). Real-world outcomes of non-responding diabetic macular edema treated with continued anti-VEGF therapy versus early switch to dexamethasone implant: 2-year results. Acta Diabetol. 56, 1341-1350. doi:10.1007/s00592-019-01416-4

Carnevali, A., Giannaccare, G., Gatti, V., Scuteri, G., Randazzo, G., and Scorcia, V. (2020). Intravitreal injections during COVID-19 outbreak: real-world experience from an Italian tertiary referral center. Eur. J. Ophthalmol. 31. doi:10.1177/1120672120962032

Ceravolo, I., Oliverio, G. W., Alibrandi, A., Bhatti, A., Trombetta, L., Rejdak, R., et al. (2020). The application of structural retinal biomarkers to evaluate the effect of intravitreal ranibizumab and dexamethasone intravitreal implant on treatment of diabetic macular edema. Diagnostics 10. doi:10.3390/ diagnostics10060413

Elfalah, M., AlRyalat, S. A., Toro, M. D., Rejdak, R., Zweifel, S., Nazzal, R., et al. (2021). Delayed intravitreal anti-VEGF therapy for patients during the COVID-19 lockdown: an ethical endeavor. Clin. Ophthalmol. 15, 661-669. doi:10.2147/OPTH.S289068 great importance in reducing the burden of injections of clinics and hospitals. Treating eligible subjects with DME showing the previously mentioned OCT biomarkers, could indeed reduce the burden of care delivery for patients and health system. Considering that the IOP increase after the injection is typically noticed within the first 2 weeks, IOP lowering eye drops together with a post-injection visit should be taken into account for patients with high risk for glaucoma.

Almost one year is gone since the WHO declared the global pandemic and new more contagious virus variants are now emerging. Physicians may be dealing with this emergency status for the next 1 or 2 years.

In our opinion, by tailoring the treatment to patients in most need, equity can be considered the ethical value that support the decisionmaking by the treating provider.

Although an evidence-based clinical practice guideline for intravitreal injections is not yet available, we believe that these considerations about management of diabetic patients with DME, could be useful for ophthalmologists from most affected countries who will be under public health COVID-19 measures and restrictions for the next months. Saving costs, resources and time is an important goal for all health workers who are facing this common enemy in first line.

\section{AUTHOR CONTRIBUTIONS}

CI wrote the first draft of the manuscript. EP, GG, VS, and AC checked and revised the draft manuscript. All authors contributed read, revised, and approved the submitted version.

Ferrara, M., Romano, V., Steel, D. H., Gupta, R., Iovino, C., van Dijk, E. H. C., et al (2020). Reshaping ophthalmology training after COVID-19 pandemic. Eye 34, 2089. doi:10.1038/s41433-020-1061-3

Gagliano, C., Toro, M., Avitabile, T., Stella, S., and Uva, M. (2015). Intravitreal steroids for the prevention of PVR after surgery for retinal detachment. Curr. Pharm. Des. 21, 4698-4702. doi:10.2174/1381612821666150909100212

He, Y., Ren, X. J., Hu, B. J., Lam, W. C., and Li, X. R. (2018). A meta-analysis of the effect of a dexamethasone intravitreal implant versus intravitreal anti-vascular endothelial growth factor treatment for diabetic macular edema. BMC Ophthalmol. 18, 121. doi:10.1186/s12886-018-0779-1

Heier, J. S., Brown, D. M., Chong, V., Korobelnik, J. F., Kaiser, P. K., Nguyen, Q. D., et al. (2012). Intravitreal aflibercept (VEGF trap-eye) in wet age-related macular degeneration. Ophthalmology 119, 2537-2548. doi:10.1016/j.ophtha.2012.09.006

Iglicki, M., Busch, C., Zur, D., Okada, M., Mariussi, M., Chhablani, J. K., et al. (2019). Dexamethasone implant for diabetic macular edema in naive compared with refractory eyes: the international retina group real-life 24-month multicenter study: the irgrel-dex study. Retina 39, 44-51. doi:10.1097/IAE. 0000000000002196

Iovino, C., Caporossi, T., and Peiretti, E. (2020a). Vitreoretinal surgery tip and tricks in the era of COVID-19. Graefes Arch. Clin. Exp. Ophthalmol. 258, 2869. doi:10.1007/s00417-020-04800-x

Iovino, C., Giannaccare, G., Pellegrini, M., Bernabei, F., Braghiroli, M., Caporossi, T., et al. (2019). Efficacy and safety of combined vitrectomy with intravitreal dexamethasone implant for advanced stage epiretinal membrane. Drug Des. Devel. Ther. 13, 4107-4114. doi:10.2147/DDDT.S229031

Iovino, C., Mastropasqua, R., Lupidi, M., Bacherini, D., Pellegrini, M., Bernabei, F., et al. (2020b). Intravitreal dexamethasone implant as a sustained release Drug delivery device for the treatment of ocular diseases: a comprehensive review of the literature. Pharmaceutics 12, 703. doi:10.3390/pharmaceutics12080703 
Korobelnik, J.-F., Loewenstein, A., Eldem, B., Joussen, A. M., Koh, A., Lambrou, G. N., et al. (2020). Guidance for anti-VEGF intravitreal injections during the COVID-19 pandemic. Graefe's Arch. Clin. Exp. Ophthalmol. 258, 1-8. doi:10. 1007/s00417-020-04703-x

Maturi, R. K., Pollack, A., Uy, H. S., Varano, M., Gomes, A. M. V., Li, X. Y., et al. (2016). Intraocular pressure in patients with diabetic macular edema treated with dexamethasone intravitreal implant in the 3-year mead study. Retina 36, 1143-1152. doi:10.1097/IAE.0000000000001004

Plyukhova, A. A., Budzinskaya, M. V., Starostin, K. M., Rejdak, R., Bucolo, C., Reibaldi, M., et al. (2020). Comparative safety of bevacizumab, ranibizumab, and aflibercept for treatment of neovascular age-related macular degeneration (amd): a systematic review and network meta-analysis of direct comparative studies. J. Clin. Med. 9, 1522. doi:10.3390/jcm9051522

Rajesh, B., Zarranz-Ventura, J., Fung, A. T., Busch, C., Sahoo, N. K., RodriguezValdes, P. J., et al. (2020). Safety of 6000 intravitreal dexamethasone implants. Br. J. Ophthalmol. 104, 39-46. doi:10.1136/bjophthalmol-2019-313991

Reibaldi, M., Russo, A., Avitabile, T., Uva, M. G., Franco, L., Longo, A., et al. (2014). Treatment of persistent serous retinal detachment in vogt-koyanagi-harada syndrome with intravitreal bevacizumab during the systemic steroid treatment. Retina 34, 490-496. doi:10.1097/IAE.0b013e3182a0e446

Reibaldi, M., Russo, A., Zagari, M., Toro, M., De Grande, V., Cifalinò, V., et al. (2012). Resolution of persistent cystoid macular edema due to central retinal vein occlusion in a vitrectomized eye following intravitreal implant of dexamethasone $0.7 \mathrm{mg}$. Case Rep. Ophthalmol. 3, 30-34. doi:10.1159/000336273

Schmidt-Erfurth, U., Garcia-Arumi, J., Bandello, F., Berg, K., Chakravarthy, U., Gerendas, B. S., et al. (2017). Guidelines for the management of diabetic macular edema by the European Society of Retina Specialists (EURETINA). Ophthalmologica 237, 185-222. doi:10.1159/000458539

Ting, D. S. W., Cheung, G. C. M., and Wong, T. Y. (2016). Diabetic retinopathy: global prevalence, major risk factors, screening practices and public health challenges: a review. Clin. Exp. Ophthalmol. 44, 260-277. doi:10.1111/ceo.12696

Tognetto, D., Brézin, A. P., Cummings, A. B., Malyugin, B. E., Evren Kemer, O., Prieto, I., et al. (2020). Rethinking elective cataract surgery diagnostics, assessments, and tools after the COVID-19 pandemic experience and beyond: insights from the EUROCOVCAT group. Diagnostics 10, 1035. doi:10.3390/diagnostics10121035

Toro, M., Choragiewicz, T., Posarelli, C., Figus, M., and Rejdak, R. (2020). Early impact of covid-19 outbreak on the availability of cornea donors: warnings and recommendations. Clin. Ophthalmol. 14, 2879-2882. doi:10.2147/OPTH. S260960

Toro, M. D., Brézin, A. P., Burdon, M., Cummings, A. B., Evren Kemer, O., Malyugin, B. E., et al. (2020). Early impact of COVID-19 outbreak on eye care: insights from EUROCOVCAT group. Eur. J. Ophthalmol. 31. doi:10.1177/ 1120672120960339

Toro, M. D., Nowomiejska, K., Avitabile, T., Rejdak, R., Tripodi, S., Porta, A., et al. (2019). Effect of resveratrol on in vitro and in vivo models of diabetic retinophathy: a systematic review. Int. J. Mol. Sci. 20. doi:10.3390/ijms20143503

Wang, C., Horby, P. W., Hayden, F. G., and Gao, G. F. (2020). A novel coronavirus outbreak of global health concern. Lancet 395, 470-473. doi:10.1016/S01406736(20)30185-9

Zur, D., Iglicki, M., Busch, C., Invernizzi, A., Mariussi, M., Loewenstein, A., et al. (2018). "OCT biomarkers as functional outcome predictors in diabetic macular edema treated with dexamethasone implant," in Ophthalmology (Elsevier Inc.)), 267-275. doi:10.1016/j.ophtha.2017.08.031

Conflict of Interest: The authors declare that the research was conducted in the absence of any commercial or financial relationships that could be construed as a potential conflict of interest.

Copyright (C) 2021 Iovino, Peiretti, Giannaccare, Scorcia and Carnevali. This is an open-access article distributed under the terms of the Creative Commons Attribution License (CC BY). The use, distribution or reproduction in other forums is permitted, provided the original author(s) and the copyright owner(s) are credited and that the original publication in this journal is cited, in accordance with accepted academic practice. No use, distribution or reproduction is permitted which does not comply with these terms. 